\title{
A Review on Complications Confronted with Skin Penetration and Assessment of Topical Formulations in Dermal Drug Development
}

\author{
Kalikrishna Praveen Gadde', Angel Treasa Alex², Alex Joesph ${ }^{1, *}$ \\ 1'Department of Pharmaceutical Chemistry, Manipal College of Pharmaceutical Sciences, Manipal, Karnataka, INDIA. \\ ${ }^{2}$ Department of Pharmaceutical Biotechnology, Manipal College of Pharmaceutical Sciences, Manipal, Karnataka, INDIA.
}

\begin{abstract}
A topical drug-delivery system is the most accepted drug delivery system. One of the pre-requisites for a topical formulation is its ability to penetrate the skin membrane to elicit the intended action. Many in vitro skin permeation studies are reported by scientists to evaluate the penetration of the drug into human skin. Several direct methods including tape stripping, in vitro percutaneous studies measures skin tissue concentration. While indirect methods like plasma collection, micro-dialysis etc. the information produced is translated and transformed to offer details of skin tissue concentration. The present review focuses on various techniques in use for the estimation of topical drugs to assess skin permeation, along with their merits and demerits and challenges encountered in them. Additionally, this review also focus on limitations in topical drug development.
\end{abstract}

Key words: Skin permeation, Microdialyis, in vitro Percutaneous Studies, Tape stripping, Skin contamination.

\section{INTRODUCTION}

The skin helps as a barrier which preserves moisture in the body and prevents the invasion of harmful exogenous substances such as irritants and allergens. The evidence reported suggesting that the 'skin barrier' have a role in the pathogenesis of a wide variety of inflammatory skin disorders, including contact dermatitis, psoriasis, atopic dermatitis and rosacea. Hence the current medicines in the treatment of these disorders are typically the anti-inflammatory and anti-proliferative compounds. ${ }^{1-3}$ Skin has been the striking area for the pharmaceutical companies as it can offer the larger therapeutic window when compared to other forms of drug delivery. Traditionally compounds have been applied to the skin to improve beauty and treat local conditions. In most cases these compounds applied topically are poorly absorbed probably due to the barrier effect of skin, size and polarity of the drug molecule. Thus they are meant to remain on the skin surface (topical) such as sunscreens, insect repellents and antiseptics while others penetrate into the skin layers (transdermal) to target sites within the skin or just below it. To treat the conditions beyond the local site of application, transdermal delivery technology have been developed. By definition medications that are applied to the top of the skin are referred as topical and here the drug produces a local effect by passive diffusion in the skin itself. While transdermal medications refer to medications that are applied to the skin but involve skin penetration enhancing technology that increase the amount of drug that can cross the skin barrier, often to the point that the drug can enter the systemic circulation and exert effects in areas other than the site of application. The formulation of dermal drugs started after 1950 with corticosteroids. Regardless of impressive effectiveness, steroid use
Submission Date: 17-06-2019; Revision Date: 18-09-2019; Accepted Date: 14-10-2019

DOI: 10.5530/ijper.53.4s.140 Correspondence: Dr. Alex Joseph, Associate Professor, Manipal College of Pharmaceutical Sciences, Manipal University, Manipal-576104, Karnataka, INDIA.

Phone: +919448548060 E-mail: alex.joseph@manipal. edu

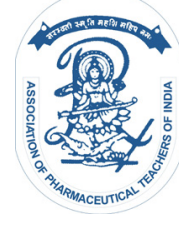

www.ijper.org 
restricted because of the serious side effects witnessed when given systemically for a long period..$^{4-6}$ The value of topically delivered hydrocortisone flagged the way for additional developments of steroid drugs. Over the years, the active development of retinoid, Vitamin D3 derivatives and immuno-suppressors have further demonstrated the dermal potential for drug target classes with complicated safety profile. In the past fifteen years the drug companies have explored new mechanisms of action of drugs rather than using same old drug. ${ }^{7-9}$ There are large number of molecules despite having some potential advantages they cannot be used as drugs since they cause serious toxic effects when delivered systemically. Later, scientists have tried to be explored topical delivery for those drugs, but notable growth was not observed since the criteria for dermal drug delivery is far more different compared to oral or systemic drug delivery. ${ }^{10}$ Considering the necessity, patient compliance and ease of drug delivery there as an ultimate need to develop topical drug candidates.

\section{Why Topical Drug Delivery System}

Topical delivery system is defined as the system which carries the drug into the contact with skin and through the skin. ${ }^{11}$ Topical drug delivery when compared with various other routes primarily with the oral approach, circumvents first pass metabolism along with other tediousness like effect of $\mathrm{pH}$, the occurrence of enzymes and gastric emptying time associated with the gastrointestinal tract. ${ }^{12-14}$ Additional benefits are: large area of application in contrast with nasal or buccal cavity, much better patient compliance and treatment ease and comfort of application, chance of self-medication, non-invasive administration, medicines with brief biological half-life and narrow therapeutic window can be employed, easiness of dose termination in the occurrence of any negative responses, straight contact to desired site, acts as an alternative in conditions where oral dosing will not be possible. ${ }^{12,14,15}$

\section{Limitations in Development of Topical Drug Delivery Compared to Oral/Systemic Drug Delivery}

The topical drug development is much more complicated than the other types of drug delivery like oral and systemic. In these types' establishment of desired (target) plasma concentration that is necessary for pharmacological effect in animal is possible. This concentration is further carried on to clinical trials 1 and 2 where the objective of trial-1 would be to find a dose that will show pharmacological action in human volunteers if this dose found to be secure in them then, it can be administered to the patients with self-confidence. ${ }^{10}$ Whereas in the topical drug development this desired plasma concentration happens to be absent, this aspect complicates the development process since, there are no well-known methods to estimate the drug in dermal tissues, it enforces several queries during drug selection stage for instance 1) pharmacology of drug 2) is enough drug reaching the desired site, these aspects further generate more questions on the proposed research concept. ${ }^{16}$ In the development process of oral drugs scientists focus on key elements such as 1) whether the drug could be able to achieve high bioavailability to avoid subject to subject variation 2) is it possible to achieve the desired plasma concentration to show the pharmacological action. In order to understand these questions researchers must have an idea about physicochemical properties of the drug. ${ }^{17-21}$ The so-called "rule of 5" has turned out to be popular as a rapid screen for compounds more likely to be poorly absorbed. ${ }^{21}$ Globally scientists have discovered four parameters that determine the solubility and permeability of a molecule they are molecular weight, $\log \mathrm{P}$, number of hydrogen bond donors and no: of hydrogen bond acceptors. These parameters need to be set in a proper manner to get the desired solubility and permeability. Rigorous analysis was carried out to screen the molecules based on these four parameters, this has led to 'rule of 5'. In the process of analysis out of these four parameters every parameter has cutoff score. Those scores has come close to 5 or multiples of 5 for high number of molecules under analysis thus, this is mnemonically called as 'rule of 5 ' ${ }^{21}$ Various other analysis has been also followed for screening of compounds. ${ }^{22-26}$ Fascinatingly, in dermal medication development, this strategy is mostly unfinished. Certainly, experts Pugh et al. and Lipinsky has found some tools to identify the rate at which the molecule penetrates and flux towards the skin are enough for a molecule to provide enough skin concentrations. ${ }^{27,28}$ Considering the effectiveness, solubility and penetrability aspects but the absence of data on the drug concentration in the skin tissue avoids such rules being recognized. Poor drug candidates are therefore, withdrawn from further development with that strategy. The solitary tool continues to be in the usage is the use of animal models. However, they show large differences in skin permeability across species. The other difficulty with topical drugs is their half-life inside the body. Currently, the idea of half-life doesn't exist in topical treatment yet.

When there is a brand-new topical candidate for setting the clinical procedure frequently requires that a topical medication needs to be administered "twice a day". Interestingly, this historical regimen was acknowledged by the patients. In case of some topical medications 
such as clobetasol propionate and fluticasone propionate, this regimen proved incorrect since the administration of drug for the single time have shown satisfactory efficacy. The circumstance of the antifungal Lamisil ${ }^{\circledR}$ (terbinafine) happens to be impressive as single dose is as effective as once a day treatment for single week. ${ }^{29}$ Nonetheless, the in-silico and PK/PD approaches have indicated exactly how they could be utilized to enhance or possibly predict pharmacology and turn into an important attribute to consider for the succeeding topical drug candidate. ${ }^{30}$

\section{Challenges Encountered in Development Topical Drug Delivery}

\section{Membrane Integrity}

Now a days mostly the skin permeation studies are performed using franz diffusion cell by means of human skin epidermis. ${ }^{31}$ Thus, it is compulsory to identify the integrity of that skin membrane under use because membranes with poor integrity are likely to give false information about drug penetration. The membrane integrity, is measured by electrical resistance and Trans Epidermal Water Loss (TEWL). ${ }^{32}$

\section{Source of Skin}

The permeation is also dependent on the skin source. Because the histology of skin is different in every species. Thus, the interchangeability of skin penetration was observed in skin from different sources was found. ${ }^{33}$

\section{Storage of Skin}

The skin is stored in a solution containing saline and glycerol because the salt increases the freezing point of the glycerol and do not encourage the formation of ice crystals hence it protects the skin cells from disruption. It is a hygroscopic viscous liquid which is odor less and colorless with three hydroxyl groups and thus enhances water absorption. Glycerol has an excellent antibacterial, antifungal and antiviral properties, as well as acts as a cry protectant for frozen tissue storage, because of its dehydrating properties resulting from strong binding to water which prevents the formation of ice crystals which otherwise may cause damage to tissues.

\section{Penetration}

Literature states that, for a topical drug to elicit its pharmacological action the primary criteria are to pass the skin barrier (stratum corneum) composed of ceramides, free fatty acids and of cholesterol as the main components, its comportment is unlike other biological membranes. ${ }^{34}$ Till the present day many several methods and models are reported by the researchers to overcome the issue of permeation to skin and enhance the drug permeation to the skin. ${ }^{35-37}$ However not all molecules suffer with the problem of penetration. Only moderately lipophilic molecules of weight $<500$ $\mathrm{Da}$ and $\log \mathrm{P}$ value 1-4 are probable to penetrate the skin well. Drugs which do not possess these physicochemical properties passive drug penetration becomes difficult. Suitable penetration improvement strategies could be used which include physical methods such as microneedles and iontophoresis or chemical methods such as use of penetration enhancers. ${ }^{38-40}$ These strategies focus on two components 1) to weaken the barrier properties 2) to vigorously drive the molecule across the skin. Penetration enhancers have occasionally been used synergistically. ${ }^{41-44} \mathrm{~A}$ study performed by Martin et al., on the range of gabapentin formulations e.g. hydrogels and creams revealed that the chemical penetration enhancement method deployed has produced remarkable improvement in penetration when ethanol and dimethyl sulfoxide used as penetration enhancers and carbopol ${ }^{\circledR}$ was used as base in hydrogels, gabapentin compounded with the proprietary Lipoderm ${ }^{\circledR}{ }^{43}$ It is also reported that there is significant penetration enhancement of minoxidil nanoemulsion with chemical penetration strategy using the oleic acid and eucalyptol as penetration enhancers. ${ }^{44}$ However, Montenegro et al. describes that enhancement of penetration is not always desirable in case of sunscreens UV filters are used which may be toxic if they reach the systemic circulation. ${ }^{45} \mathrm{He}$ formulated different formulations with UV filters, have shown penetration into the skin which is undesirable since they cause toxic effects. Hence one should be cautious while selecting the excipients for topical formulations.

\section{Estimation of Drug Concentration in Skin}

Estimation of drug in the skin layers turn out to be very challenging job. Subsequently it involves skilled personnel to perform the task. Drug estimation in skin comprises of many stages while performing the experiment which needs to be handled carefully to evade the incorrect results. To assess the pharmacokinetics of a drug in the skin, numerous methods are described by the experts. At this point we discuss about the methods which are accepted and used globally for day-to-day analysis along with their pros and cons. These methods are classified as direct methods which are often in vitro/ ex vivo methods and indirect methods which are often referred as in vivo methods.

\section{Direct Methods}

\section{Tape stripping}

This method is extensively utilized for the determination of drug concentration inside the Stratum corneum for 
the drug applied topically. There is FDA guidance on this method and the method is beneficial to demonstrate the bioequivalence among two topical formulations. It is conducted by mounting skin on the cells of Franz diffusion apparatus subsequently drug is applied and the residual drug is eliminated by rubbing or washing then the drug present on the Stratum corneum is removed by sequential tape strips of adhesive tape. Finally, the drug content of those strips is determined.

As Stratum corneum being the very first layer of the skin, it is easy to sample and estimate the drug through an analytical method since higher concentrations of the drug are present in upper layers. The technique has been used over the years because the quantification of the level of drug in Stratum corneum drastically improves the quality of the data produced and this strategy can be used in vitro and is comparatively non-invasive. However, there are several questionable issues associated with this method which are discussed in the following section.

Stratum corneum is the target of drug delivery just in the case of sunscreens and antifungals the debatable issue of cleansing procedure (skin surface contamination issue) which is an important issue which will be addressed later in the review. Accounting the first strip or not is yet another concern with the method, the literature reveals the inconsistency of tape stripping method in the establishment of bioequivalence and that questions the information produced from tape stripping. ${ }^{46}$ Adopting the conflicting information from the two expert laboratories on bioequivalence, the FDA removed the draft guidance on tape stripping in the year 2002 which had been published in 1998..$^{47,48}$ The evidence shows that the microdialysis technique draws diverse conclusions for bioequivalence as compared to tape stripping. Microdialysis is a cumbersome method with limitations, although the contamination challenges are certainly not found and the data generated is of good quality. ${ }^{49-52}$ Skin contamination issue occur in this method as the device utilized for the skin biopsy may possibly carry a little drug which is unremoved during surface washing. Some inconsistencies of data is reported by Surber et al. The other problem with this procedure is it determines the skin concentration of both bound and unbound drug despite the fact we need only the unbound drug concentration. ${ }^{53,54}$

\section{In vitro Percutaneous Studies}

The process involves determining drug concentration inside the different skin tissues after topical drug application in vitro. Usually, after elimination of the analyzed topical formulation from the skin surface, the Stratum corneum is tape stripped, the epidermis as well as der- mis are subsequently detached. Concentration in the three distinct tissues is exposed at that point. This can be performed effortlessly in vitro and offers in vitro drug concentration in all skin tissues. But skin contamination issue is found and it determines the concentration of both bound and unbound drug

\section{Challenges Encountered in the Performance of Direct Methods}

The most significant concern is "Skin contamination issue" it takes place in the circumstances like, when the drug is applied on the skin the magnitude of drug which penetrates is quite less to that of the quantity of medicine which stays on the skin surface so, to get rid of that drug appropriate cleaning procedure needs to be established to precisely quantify the portion of drug penetrated in to the skin tissue. ${ }^{55}$ This task is attainable theoretically on a surface that is smooth, impermeable and hard but this happens significantly less with the human skin, which is porous, robust and soft. The small amount of drug applied on the skin dries up entirely during the experiment and from the situation mentioned previously, we can realize that there must be a validated cleaning procedure to eliminate the drug applied on the skin. From the table shown (Table 1) we can see that only $0.24 \%$ of drug is permeated from the formulation, hence there is a need of effective washing procedure such that one can find sureness in reporting the dose recovered inside the skin tissue. Therefore the difficulty is that it is not feasible to validate the washing procedure protocol as validation of the protocol could often happens at time $t_{0}$ period of formulation application which is considered as option 1 or perhaps at later time $t$ which is considered as option 2 as shown in Figure 1.

With option 1, the formulation is still a semi-solid, for this reason it is practically too easy to sample and remove which is considered to be less difficult than to sample after the formulation has dried as in option 2 . Even though the sampling in case of option 1 is less difficult the results of samples analysis shows inconsistent results because human skin is porous and smooth making the validation of the cleaning procedure difficult. Whereas in case of option 2 sampling cannot be performed once the formulation had become dry

\begin{tabular}{|c|c|}
\hline Amount of formulation applied $\left(\mathrm{mg} / \mathrm{cm}^{2}\right)$ & 20 \\
\hline Drug applied $\left(\mu \mathrm{g} / \mathrm{cm}^{2}\right)$ & 200 \\
\hline Average flux through skin over $24 \mathrm{~h}\left(\mathrm{ng} / \mathrm{cm}^{2} / \mathrm{h}\right)$ & 20 \\
\hline Quantity permeated in $24 \mathrm{~h} / \mathrm{cm}^{2}(\mu \mathrm{g})$ & 0.48 \\
\hline Dose permeated vs dose applied (\%) & 0.24 \\
\hline
\end{tabular}




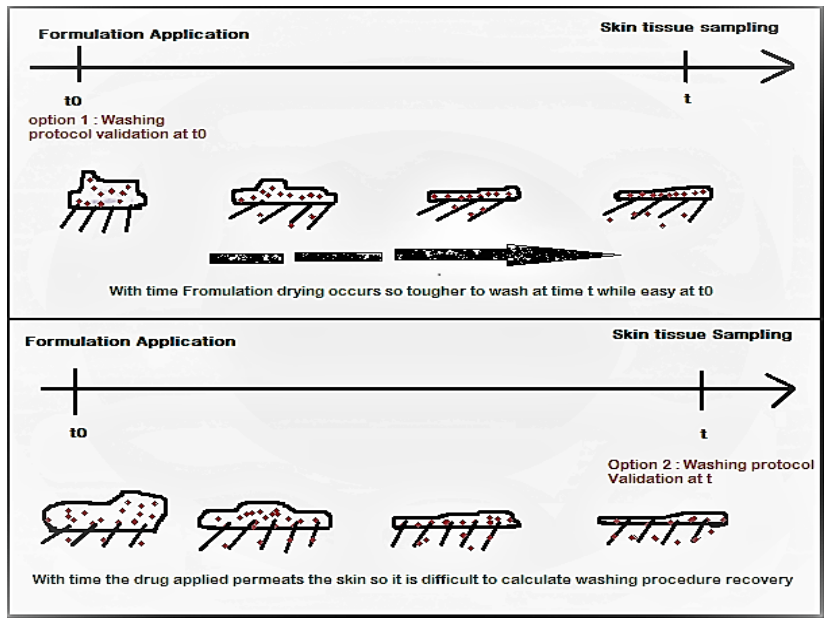

Figure 1: Efforts made to validate the washing procedure.

into a thin matrix in the Stratum corneum because by that time some drug material would have penetrated the skin. This makes validation impossible to perform as the dose recovery will be difficult. This makes any validation, impossible to perform. As a result of these limitations these direct procedures often face with the problem of overestimation of the drug. In order to minimize this skin contamination issue, one can consider not to count the stratum corneum. This might be achieved by tape stripping as this ought to eliminate the drug stuck on the skin surface. The limitation with this method is removal of Stratum corneum cannot performed homogeneously. The appearence of a glistening layer confirms the complete removal of Stratum corneum and counting the number of tapes is not a reliable method to confirm the complete removal of stratum corneum. This is difficult to observe the appearance of glistening layer in vitro and is better noticeable in vivo. Moreover, there is no uniformity in this technique as shown in the Figure 2 where part of the Stratum corneum could remain existing which could overestimate the epidermis concentration. The other problem that could encounter is to establish a proportionality between percutaneous flux and concentration in the skin. Knowing the fact that retention of drug in the viable epidermis and dermis is not possible, proportionality should exist between flux and skin concentration. When this does not happen, a strong suspicion needs to point towards a contamination of the epidermis tissue sampled.

\section{Indirect Methods}

These techniques are much less convenient in comparison with direct processes. Certainly, they usually require a lot of more subtle bio analysis techniques and the information produced need to be translated and transformed to offer details on your skin tissue concentra-

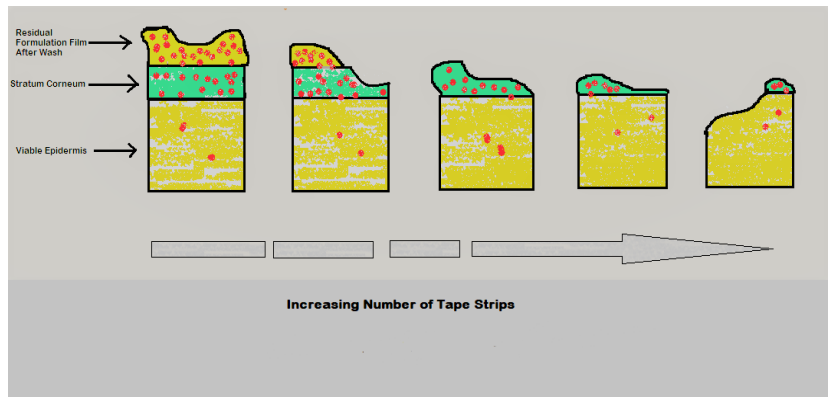

Figure 2: Tape stripping of the Stratum corneum.

tion. This brings up a bit of discomfort and occasionally, absence of self confidence in such methods and data as a result of the struggle in their interpretation. In case they are considerably more bothersome to understand, they don't possess the skin surface contamination issue and consequently, these are distinctive related to direct methods. Various other advantages of this specific techniques are concentration obtained is only of unbound drug while in direct ways, solely total tissue concentration is attained.

\section{Plasma Collection}

By this method the bioavailability of the drug can be assessed through collection of plasma. One can know about the total percutaneous flux of the drug provided the systemic clearance of the drug is already established. ${ }^{56}$ If excreta samples are used to identify the concentration of the drug, then the drug applied must be radiolabeled or larger amount of the drug must be eliminated in unchanged form and this proportion must be well defined. The advantage of this method is that it can be employed in the advancement of oral drugs since it is a relatively non-invasive and most importantly the skin contamination issue is not associated with this technique. Nevertheless, the proportionality between drug in plasma or excreta with respect to drug present in different layers of the skin is not well established. Generally, concentrations of the topically applied drugs in the plasma or excreta are very low. Hence very sensitive analytical techniques are necessary for the quantification. The other potential limitation with this method is while performing preclinical studies on rats, contamination of blood samples might occur since the drugs are applied on the skin. The other aspect is rats are frequently involved in grooming behavior which may remove the drug from the site of application

\section{Microdialysis}

Through this technique the concentration of drug in the extracellular space of the skin can be measured. It involves insertion of microdialyis fibers into the skin. Subsequently the fiber is perfused with physiological 


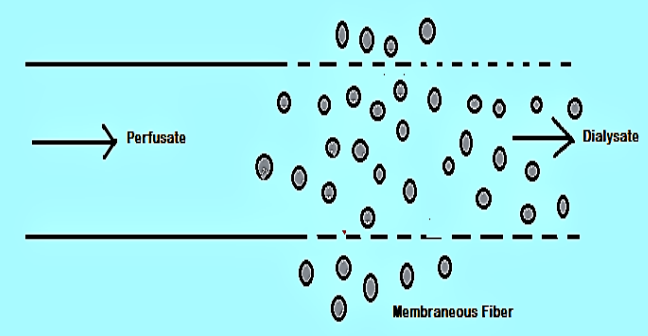

Figure 3: Principle of microdialysis sampling by a linear fiber.

fluid which gathers tiny molecules around the fiber. The sample recovered from the fiber is protein free. This is used to decrease the inflammation caused due to insertion of fiber. Later drug is applied above the area where fiber was inserted. Afterwards a little amount of sample is collected.$^{57}$ Holmgaard et al. have specified the method evidently (Figure 3). The perfusate is pumped through the fiber at a predetermined low flow rate. The perfusate passes through the membranaceous portion, which is 1 to $4 \mathrm{~cm}$ long during which the dispersion of small molecules across the membrane takes place. The perfusate here is termed as dialysate. ${ }^{58}$ There happens to be two cases in this method first case includes simply measuring the concentration of fluid collected, which is proportional to concentration in the dermis and in this case critical parameter to be established is recovery from the microdialysis fibers (micro dialysis fiber recovery factor) which is needed to define the extracellular concentration of drug. The latter case is following no net flux method (NNF). In this method 4-6 fibers are infused each fiber cover individual concentration the range prescribed. Final recovery from dermis corresponds to infused concentration i.e. there is no change in concentration infused and recovered.

This method is in vivo and there is zero "contamination issue" provided that the factors of entrance and exit of the fiber in and out of your skin are well separated from the spot where the topical drug is applied. Another advantage of this method is this method uses a small area which limits the exposure and therefore the toxicity issues. However, this is somewhat tricky method and invasive method to set up. The drug concentration within the samples is usually low, particularly with lipophilic permeants. Measurement of such low levels will require the use of competent analytical techniques typically. Validity of the concentration defined is determined by the "microdialysis fibre recovery factor" used, which is established beyond the in vivo quality and is typically poorly estimated. ${ }^{59-61}$ However the retrodialysis technique when utilized in vivo as discussed by Stahle et al. is recognized as a right way of estimating in vivo restoration and it is being used by an expanding number of microdialysis groups as an abbreviated technique of the NNF strategy as it doesn't need equilibration. ${ }^{2}$ It also involves lengthy equilibration time and dependable microdialysis fibres (that don't block over time). ${ }^{63}$ Although this method has some limitations in the drug discovery stage this method is well suited for bioequivalence studies.

\section{CONCLUSION}

The success of a topical formulation depends on its ability to penetrate the skin membrane to elicit the intended action. Although many in vitro skin permeation studies like direct and indirect methods are available to the scientists to evaluate the penetration of the drug through the human skin. Indirect methods like microdialysis technique was found to be the best as it gives all possible information. However tough analytical issues do not make the microdialysis as appropriate technique during dermal drug development process especially at drug discovery stage. The other techniques give the required information regarding the tissue concentration but there are reported limitations as we have discussed in this review. The only method other than microdialysis not having skin contamination issue is plasma collection and in vitro percutaneous study. However, in percutaneous study also the link between tissue concentration and plasma concentration is not known. Totally, it gives the impression that none of the presently existing techniques assist in quantifying the concentration of drug in the skin after the topical application. All the methods are either defective with the skin contamination issue combined with concentration determination issue attributed due to determination of both unbound and bound drug levels but not the desired unbound drug or they are very complex to use as tools during the drug discovery stage or per se they do not effectively determine the skin concentration. Looking at these challenges one should be very cautious while selecting the drug candidate for the topical drug delivery.

\section{ACKNOWLEDGEMENT}

The authors are thankful to the principal of Manipal College of Pharmaceutical Sciences, Manipal for his support and encouragement in writing this review.

\section{CONFLICT OF INTEREST}

The authors have no conflict of interest. 


\section{ABBREVIATIONS}

PK/PD: $\quad$ Pharmacokinetics/Pharmacodynamics; TEWL: Trans Epidermal Water Loss; FDA: Food and Drug Administration; NNF: Net Flux Method.

\section{REFERENCES}

1. Yamasaki K, DiNardo A, Bardan A, Murakami M, Ohtake T, Coda A, et al. Increased serine protease activity and cathelicidin promotes skin inflammation in rosacea. Nat Med. 2007;13(8):975-80.

2. Cork MJ, Danby SG, Vasilopoulos Y, Hadgraft J, Lane ME, Moustafa M, et al. Epidermal barrier dysfunction in atopic dermatitis. J Invest Dermatol. 2009;129(8):1892-908

3. Proksch E, Brandner JM, Jensen JM. The skin: An indispensable barrier. Exp Dermatol. 2008;17(12):1063-2.

4. Denda M, Wood LC, Emami S, Calhoun C, Brown BE, Elias PM, et al. The epidermal hyperplasia associated with repeated barrier disruption by acetone treatment or tape stripping cannot be attributed to increased water loss. Arch Dermatol Res. 1996;288(5-6):230-8.

5. Wood LC, Jackson SM, Elias PM, Grunfeld C, Feingold KR. Cutaneous barrier perturbation stimulates cytokine production in the epidermis of mice. $\mathrm{J}$ Clin Invest. 1992;90(2):482-7.

6. Clark SC, Zirwas MJ. Management of occupational dermatitis. Dermatol Clin. 2009;27(3):365-3.

7. Darsow U, Wollenberg A, Simon D, Taieb A, Werfel T, Oranje A, et al. ETFAD/ EADV eczema task force 2009 position paper on diagnosis and treatment of atopic dermatitis. J Eur Acad Dermatol Venereol. 2009;24(3):317-28.

8. Laws PM, Young HS. Topical treatment of psoriasis. Expert Opin Pharmacother. 2010;11:1999-9.

9. Scheinfeld N, Berk T. A review of the diagnosis and treatment of rosacea. Postgrad Med. 2010;122(1):139-43.

10. Trottet $\mathrm{L}$, Maibach $\mathrm{H}$. Topical versus oral/systemic drug delivery. In: Dermal Drug Selection and Development. An Industrial Prespective, $1^{\text {st }}$ edn. Cham, Switzerland: Springer international AG. 2017;39-7.

11. Weiss SC. Conventional topical delivery systems. Dermatol Ther. 2012;24(5):471-6.

12. Brown MB, Martin GP, Jones S, Akomeah FK. Dermal and transdermal drug delivery systems: Current and future prospects. Drug Deliv. 2006;13(3):175-7.

13. Vaishali A, Praveen KRS. Emulgels: A Review for Topical Drug Delivery of Hydrophobic Drugs. Int J Pharm Prof Res. 2015;6(3):1256-3.

14. Kaur J, Kaur J, Jaiswal S, Gupta GD. Recent Advances in Topical Drug Delivery System. Indo Am J Pharm Res. 2016;6(7):6353-9.

15. Kute SB, Saudagar RB. Emulsified gel A Novel approach for delivery of hydrophobic drugs: An overview. J Adv Pharm Edu Res. 2013;3(4):368-6.

16. Morgan P, DerGraaf VPH, Arrowsmith J, Feltner DE, Drummond KS, Wegner $\mathrm{CD}$, Street SD. Can the flow of medicines be improved? Fundamental pharmacokinetic and pharmacological principles toward improving phase II survival. Drug Discov Today. 2012;17(9-10):419-4.

17. Navia MA, Chaturvedi PR. Design principles for orally bioavailable drugs. Drug Discov Today. 1996;1(5):179-9.

18. Chan $\mathrm{OH}$, Stewart $\mathrm{BH}$. Physicochemical and drug delivery considerations for oral drug bioavailability. Drug Discov Today. 1996;1(11):461-73.

19. Norinder U, Osterberg T, Artursson P. Theoretical calculation and prediction of Caco-2 cell permeability using Mol Surf parametrization and PLS statistics. Pharm Res. 1997;14(12):1786-1.

20. Osterberg $\mathrm{T}$, Norinder U. Prediction of drug transport processes using simple parameters and PLS statistics. The use of ACD/logP and ACD/Chem Sketch descriptors. Eur J Pharm Sci. 2001;12(3):327-7.

21. Lipinski CA, Lombardo F, Dominy BW, Feeney PJ. Experimental and computational approaches to estimate solubility and permeability in drug discovery and development settings. Adv Drug Deliv Rev. 2001;46(1-3):3-26.

22. Bergström CAS, Strafford M, Lazorova L, Avdeef A, Luthman K, Artursson P. Absorption classification of oral drugs based on molecular surface properties. J Med Chem. 2003;46(4):558-70.
23. Varma MV, Obach RS, Rotter C, Miller HR, Chang G, Steyn SJ, et al. Physicochemical space for optimum oral bioavailability: contribution of human intestinal absorption and first-pass elimination. J Med Chem. 2010;53(3):1098-8.

24. Lovering F, Bikker J, Humblet C. Escape from flatland: Increasing saturation as an approach to improving clinical success. J Med Chem. 2009;52(21):6752-6.

25. Veber DF, Johnson SR, Cheng HY, Smith BR, Ward KW, Kopple KD. Molecular properties that influence the oral bioavailability of drug candidates. J Med Chem. 2002;45(12):2615-23.

26. Bhal SK, Kassam K, Peirson IG, Pearl GM. The rule of five revisited: applying $\log D$ in place of $\log P$ in drug-likeness filters. Mol Pharm. 2007;4(4):556-60.

27. Pugh WJ, Hadgraft J, Roberts MS. Physiochemical determinants of Stratum corneum permeation. Dermal absorption and toxicity assessment, New York: Marcel Dekker; 1998;91:245-68.

28. Lipinski CA, Lombardo F, Dominy BW, Feeney PJ. Experimental and computational approaches to estimate solubility and permeability in drug discovery and development settings. Adv Drug Deliv Rev. 2001;46(1-3):3-26.

29. Evans EG, Seaman RA, James IG. Short-duration therapy with terbinafine $1 \%$ cream in dermatophyte skin infections. Br J Dermatol. 1994;130(1):83-7.

30. Trottet L, Maibach H. Assessing Topical Efficacy. In: Dermal Drug Selection and Development. An Industrial Prespective, $1^{\text {st }}$ edn. Cham, Switzerland: Springer international AG. 2017;69-86.

31. Musazzi UM, Casiraghi A, Franzé S, Cilurzo F, Minghetti P. Data in Brief Data on the determination of human epidermis integrity in skin permeation experiments by electrical resistance. Data Brief. 2018;21:1258-62.

32. Chiang A, Tudela AE, Maibach HI. Percutaneous absorption in diseased skin: An overview. J Appl Toxicol. 2012;32(8):537-3.

33. Eloy JO, Petrilli R, Campos PM. Evaluation of critical parameters for in vitro skin permeation and penetration studies using animal skin models. Eur $\mathrm{J}$ Pharm Sci. 2018;111:121-32.

34. Sinkó B, Garrigues TM, Balogh GT, Nagy ZK, Tsinman O, Avdeef A, et al. Skin-PAMPA: A new method for fast prediction of skin penetration. Eur $\mathrm{J}$ Pharm Sci. 2012;45(5):698-707.

35. Alkilani AZ, Mccrudden MTC, Donnelly RF. Transdermal Drug Delivery: Innovative Pharmaceutical Developments Based on Disruption of the Barrier Properties of the stratum corneum. Pharmaceutics. 2015;7(4):438-70.

36. Iqbal B, Ali J, Baboota S. Recent advances and development in epidermal and dermal drug deposition enhancement technology. Int $\mathrm{J}$ Dermatol. 2018;57(6):646-60.

37. Ng KW. Penetration Enhancement of Topical Formulations. Pharmaceutics. 2018;10(2):51.

38. Virginia M, Alicia LC, Begoña DC. Iontophoresis for Therapeutic Drug Delivery and Non-invasive Sampling Applications: Percutaneous Penetration Enhancers Physical Methods in Penetration Enhancement $1^{\text {st }}$ edn. Berlin/ Heidelberg, Germany: Springer. 2017;77-101.

39. Williams AC, Barry BW. Penetration enhancers. Adv Drug Deliv Rev. 2004;56(5):603-8.

40. Lane ME. Skin penetration enhancers. Int J Pharm. 2013;447(1-2):12-21.

41. Ng KW, Lau WM, Williams AC. Synergy between Chemical Penetration Enhancers. Percutaneous Penetration Enhancers Physical Methods in Penetration Enhancement $1^{\text {st }}$ edn. Berlin/Heidelberg, Germany: Springer. 2017;373-5.

42. Mitragotri S, Ray D, Farrell J, Tang H, Yu B, Kost J, et al. Synergistic effect of low frequency ultrasound and sodium lauryl sulfate on transdermal transport. J Pharm Sci. 2000;89(7):892-900.

43. Ng KW. Penetration Enhancement of Topical Formulations. Pharmaceutics. 2018;10(2):51.

44. Abd E, Benson H, Roberts M, Grice J. Minoxidil skin delivery from nanoemulsion formulations containing eucalyptol or oleic acid: Enhanced diffusivity and follicular targeting. Pharmaceutics. 2018;10(1):E19.

45. Montenegro L, Turnaturi $\mathrm{R}$, Parenti $\mathrm{C}$, Pasquinucci $\mathrm{L}$. In vitro evaluation of sunscreen safety: Effects of the vehicle and repeated applications on skin permeation from topical formulations. Pharmaceutics. 2018;10(1):E27.

46. Nylander-French LA. Understanding dermal exposure-a critical step in exposure assessment. Superfund Basic Research Program: Research Briefs. 2008;166

47. Surber C, Schwarb FP, Smith EW. Tape-stripping technique. Percutaneous absorption, $3^{\text {rd }}$ ed. New York: Marcel Dekker. 1999;395-409. 
48. Shah V. Topical drug products-regulatory requirements (USA). Dermal Drug Selection and Development: An Industrial Perspective. 2009;1-72. Available from:https://www.ipapharma.org/pdf/speaker/1.02\%20Vinod $\% 20$ Shah $\% 20$ topical.pdf

49. Dotzel MM. Draft guidance for industry on topical dermatological drug product NDAs and ANDAs-in vivo bioavailability, bioequivalence, in vitro release and associated studies: withdrawal. U Fed Regist. 2002;67(96):35122-3.

50. Garcia OP, Hansen SH, Shah VP, Sonne J, Benfeldt E. Are marketed topical metronidazole creams bioequivalent? Evaluation by in vivo microdialysis sampling and tape stripping methodology. Skin Pharmacol Physiol. 2011;24(1):44-3.

51. Incecayir T, Agabeyoglu I, Derici U, Sindel S. Assessment of topical bioequivalence using dermal micro-dialysis and tape stripping methods. Pharm Res. 2011;28(9):2165-75.

52. Schaefer H, Stüttgen G, Zesch A, Schalla W, Gazith J. Quantitative determination of percutaneous absorption of radiolabeled drugs in vitro and in vivo by human skin. Curr Probl Dermatol. 1978;7:80-94.

53. Surber C, Smith EW, Schwartz FP, Maibach HI. Drug concentration in skin: Percutaneous absorption: drugs, cosmetics, mechanisms, methodology, New York: Marcel Dekker. 1999;347-74.

54. Fitzgerald GG. Pharmacokinetics and drug metabolism in animal studies (ADME, protein binding, mass balance, animal models): Integration of pharmacokinetics, pharmacodynamics and toxicokinetics in rational drug development. New York: Plenum Press. 1993;23-31.

55. Trottet L, Maibach H. Assessing Drug Concentration in Skin: Direct and Indirect Methods. In: Dermal Drug Selection and Development. An Industrial
Prespective, $1^{\text {st }}$ edn. Cham, Switzerland: Springer international AG. 2017;4967.

56. Hadgraft J, Hill S, Hümpel M, Johnston LR, Lever LR, Marks R, et al. Investigations on the percutaneous absorption of the antidepressant rolipram in vitro and in vivo. Pharm Res. 1990;7(12):1307-12.

57. Benfeldt E. In vivo micro dialysis for the investigation of drug levels in the dermis and the effect of barrier perturbation on cutaneous drug penetration. Studies in hairless rats and human subjects. Acta Derm Venereol Suppl. 1999;206:1-59.

58. Holmgaard R, Nielsen JB, Benfeldt E. Microdialysis sampling for investigations of bioavailability and bioequivalence of topically administered drugs: Current state and future perspectives. Skin Pharmacol Physiol. 2010;23(5):225-43.

59. Benfeldt E, Serup J, Menne T. Microdialysis vs. suction blister technique for in vivo sampling of pharmacokinetics in the human dermis. Acta Derm Venereol. 1999;79(5):338-42.

60. Gunaratna C, Lunte SM, Zuo H. Shunt probe: A new microdialysis probe design for in vivo drug metabolism studies. Curr Sep. 1994;13:80-3.

61. Holmgaard R, Nielsen JB, Benfeldt E. Skin permeation assessment Microdialysis. Transdermal and Topical Drug Delivery: Principles and Practice. US: John Wiley and Sons, Inc. 2012;131-3.

62. Stahle L, Segersvard S, Ungerstedt U. A comparison between three methods for estimation of extracellular concentrations of exogenous and endogenous compounds by microdialysis. J Pharmacol Methods. 1991;25(1):41-52.

63. Schreiner A, Hellum KB, Digranes A, Bergman I. Transfer of penicillin G and ampicillin into human skin blisters induced by suction. Scand $\mathrm{J}$ Infect Dis Suppl. 1978;14:233-7.
PICTORIAL ABSTRACT

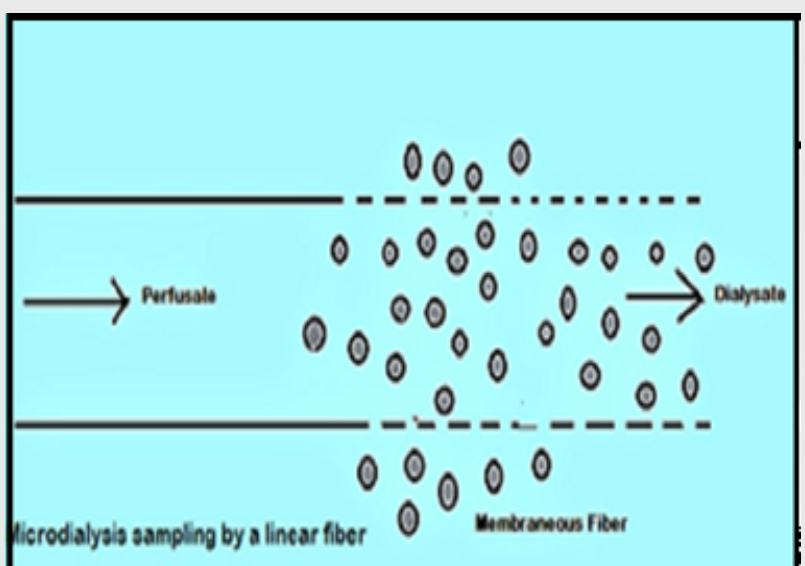

\section{SUMMARY}

- The topical drug development is very difficult process since there are lot of critical parameters such as drug penetration, estimation which still need to be developed in a way to overcome the challenges such that the data produced is reliable and confident.

- Hence development of a better, low cost penetration enhancement strategies and validated method to determine the concentration of drug in skin would be helpful in future of topical drug development.

\section{About Authors}

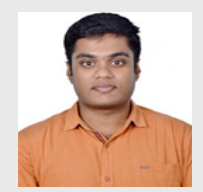

Mr. Kalikrishna Praveen Gadde, Has completed M.pharm in pharmaceutical analysis from Manipal College of Pharmaceutical sciences, Manipal Academy of Higher Education, Manipal, Karnataka, India. Currently employed in Novartis Health care Ltd. as Associate Scientist-1 
Dr. Angel Treasa Alex, Is presently working as an Assistant Professor (Senior Scale) at Department of Pharmaceutical Biotechnology, Manipal College of Pharmaceutical Sciences, Manipal Academy of Higher Education, Manipal, Karnataka, India. Dr.Angel is engaged in teaching and research since eight years. She has more than 17 research articles in peer reviewed journals and also contributed several book chapters. She is a life member of Association of Pharmaceutical Teachers of India (APTI) and also a reviewer and editorial board member of various peer reviewed journals. She has been awarded twice with good teacher award and also recently awarded with TMA gold medal for best research paper.

Dr. Alex Joseph, Is presently working as an Associate Professor at Department of Pharmaceutical Chemistry, Manipal College of Pharmaceutical Sciences, Manipal Academy of Higher Education, Manipal, Karnataka, India. Dr. Alex is engaged in teaching and research since 17 years. He has more than 41 research articles in peer reviewed journals and also contributed several book chapters. He is a life member of Association of Pharmaceutical Teachers of India (APTI) and also a reviewer and editorial board member of various peer reviewed journals. He has been awarded thrice with good teacher award and his area of research interest is in design and synthesis of novel heterocyclic compounds as anticancer, anti-inflammatory and antidiabetic agents.

Cite this article: Gadde KP, Alex AT, Joesph A. A Review on Complications Confronted with Skin Penetration and Assessment of Topical Formulations in Dermal Drug Development. Indian J of Pharmaceutical Education and Research. 2019;53(4s):s466-s474. 